\title{
Development of a pictorial scale for assessing functional interference with chronic pain: the Pictorial Pain Interference Questionnaire
}

This article was published in the following Dove Press journal: Journal of Pain Research

\author{
Andrew J Cook' \\ David A Roberts ${ }^{2}$ \\ Karen C Nelson ${ }^{3}$ \\ Brian R Clark ${ }^{4}$ \\ B Eugene Parker Jr ${ }^{4}$ \\ 'Department of Psychiatry and \\ Behavioral Science, Texas A\&M Health \\ Science Center College of Medicine, \\ Temple, TX, USA; 'ㄹiceutical \\ Labs, Charlottesville, VA, USA; \\ ${ }^{3}$ Southcentral Foundation, Anchorage, \\ AK, USA; ${ }^{4}$ Barron Associates, Inc., \\ Charlottesville, VA, USA
}

Background: Assessment of function and functional interference is an important component of chronic pain assessment and treatment and is commonly based on self-report questionnaires. Existing questionnaires for assessing functional interference are language dependent, which can limit their utility for patients across cultures with literacy, fluency, or cognitive restrictions.

Objective: The objectives of this study were to create a tool with minimal language dependence and literacy requirement for measuring functional interference due to chronic pain and evaluate the psychometric properties and usability of this new assessment scale, the Pictorial Pain Interference Questionnaire (PPIQ), in a clinical sample of participants with chronic pain. Design: The study employed a prospective, cross-sectional design in a clinical chronic pain setting.

Participants and methods: A total of 113 participants with chronic non-cancer pain were recruited from a private chronic pain clinic. A pictorial scale was developed and tested via psychometric procedures, including comparisons with validated measures of functional interference and related chronic pain constructs.

Results: Excellent internal consistency reliability ( $a=0.91)$, good construct validity (total score: $r=0.72-0.81$ ), and adequate-to-good convergent and discriminant validities were demonstrated through comparative analyses with existing self-report questionnaires. A scoring metric for classifying low, moderate, and high levels of interference was found to have good construct validity. Evaluation of satisfaction revealed adequate understanding of the PPIQ among most users.

Conclusion: Initial support for the PPIQ as an alternative to language-based questionnaires for assessing functional interference from chronic pain was found. Subsequent research will help to clarify psychometric properties of the PPIQ and user response among various chronic pain subgroups. Keywords: chronic pain, assessment, function, functional interference, impairment, disability, patient-reported outcomes, health literacy

\section{Introduction}

Functional interference is a highly prevalent consequence of chronic pain, resulting in reduced quality of life and substantial personal, societal, and economic losses. ${ }^{1-4}$ Assessment of functional interference is an important component of chronic pain assessment and treatment. It has been reported that

$[\ldots]$ perhaps more than any other dimension of the pain experience, interference with activity is a crucial predictor of future adjustment among patients with chronic pain [...]. Hence, considerable attention has been given to the development of instruments that facilitate the assessment of pain-related disability. ${ }^{5}$
Correspondence: Andrew J Cook Department of Psychiatry and Behavioral Science, Texas A\&M Health Science Center College of Medicine, 240I S. 3 I st St., Medical Education Building, Temple, TX 765048, USA Tel +l 6828003555

Email Andrew.Cook1775@gmail.com 
In clinical settings, assessment of functioning and related interference plays an increasingly important role as a measure of treatment efficacy for chronic or persistent pain, as a supplement or alternative to pain severity or intensity ratings.

Assessment of functional interference is commonly based on self-report questionnaires. ${ }^{3,5}$ As one of the three primary approaches to physical function assessment for chronic pain, self-report questionnaire assessment is recommended in clinical trial guidelines for chronic pain in addition to measures of physical function and activity levels. ${ }^{6}$ Widely employed questionnaires include the following: Oswestry Disability Index (ODI), ${ }^{7}$ Pain Disability Index (PDI), ${ }^{5,8}$ Multidimensional Pain Inventory-Interference (MPI-Int) scale, ${ }^{9}$ and Roland-Morris Disability Questionnaire (RMDQ).${ }^{10}$ Several compendiums of functional interference or health-related quality of life measures have been published, ${ }^{3,11,12}$ and computer adaptive testing item banks established. ${ }^{13,14}$

Existing standardized assessment questionnaires for functional interference are language dependent. This can limit their utility for patients with low education and literacy levels, no or limited proficiency in the language of the assessment, or mild cognitive impairment (e.g., early dementia and traumatic brain injury). Census data from 2011 revealed that, of 61 million US residents who spoke a language other than English at home, over 22\% spoke English "not well" or "not at all." ${ }^{15}$ Patients with limited English proficiency (LEP) face barriers to effectiveness and safety in health care, ${ }^{16}$ resulting in a safety advisory from the Joint Commission for health care accreditation. ${ }^{17}$ Language barriers for LEP patients are likely to result in fewer health care visits and delays in preventative services among other problems. ${ }^{18}$ Cognitive impairment affects $>16$ million individuals in the US. ${ }^{19}$ For older adults, the prevalence rate for mild cognitive impairment in the community has been estimated to exceed $20 \%{ }^{20}$ with higher rates among older adults in long-term care. ${ }^{21}$

Standardized USA grade equivalency reading levels (Flesch-Kincaid Grade Level score) ${ }^{22}$ and reading ease scores (Flesch Reading Ease [FRE] test) ${ }^{23}$ for common chronic pain functional interference questionnaires are PDI (10.0, 46.8), ODI (6.9, 62.7), MPI-Int (8.1, 62.4), and RMDQ (3.9, 87.8). Goals of 7.0-8.0 grade equivalency and 60-70 FRE are common for text aimed at the general public. All questionnaires have been translated into other languages, ${ }^{24-28}$ which is a time-consuming and costly process that increases the population of potential users, one language at a time. Guidelines for translation recommend using back-translation, committee review, and other procedures to achieve semantic, idiomatic, experiential, and conceptual equivalence in translation. ${ }^{29}$
Pictorial questionnaires provide an alternative to languagedependent tools. Applications in pain assessment include faces and other pictorial scales for pain severity, ${ }^{30,31}$ commonly used with pediatric and communication-impaired patients, and assessment of pain-related fear. ${ }^{32}$ Pictorial questionnaires have been developed and validated for a wide range of physical and mental health symptoms and disorders, including body mass index, ${ }^{33}$ nausea, ${ }^{34}$ illness-related suffering, ${ }^{35}$ pediatric psychiatric disorders,${ }^{36,37}$ psychological distress, ${ }^{38}$ and emotional response. ${ }^{39}$

The objectives of this study were to create a tool with minimal language dependence and literacy requirement for measuring functional interference due to chronic pain and evaluate the psychometric properties and usability of this new assessment scale, the Pictorial Pain Interference Questionnaire (PPIQ), in a clinical sample of participants with chronic pain.

\section{Participants and methods Participants}

Patients with chronic pain receiving treatment at a private multidisciplinary pain management clinic were recruited for participation in a parent study of multidimensional pain assessment measures. The sample included consecutive patients recruited over a period of 12 weeks. Eligibility criteria were as follows: presenting for the assessment or treatment of chronic non-cancer pain and aged 18 years or older. Patients were excluded from participation if they reported being illiterate or unable to read and complete the written study questionnaires. A total of 113 participants met eligibility criteria; all provided written informed consent for participation and completed the study procedures. Study procedures were reviewed and approved by the institutional review board of the University of Texas at Tyler. Consenting participants received no compensation for their participation. Participants were $79 \%$ female, ranged in age from 19 to 76 years $(M=50.6, \mathrm{SD}=14.2)$ and predominantly had back and lower extremity pain. The majority were married and had at least a high school education. Demographics and pain characteristics are provided in Table 1.

\section{Measures PPIQ}

The authors created a bank of 30 assessment items for functional interference from chronic pain as part of a project on multidimensional chronic pain assessment. ${ }^{14} \mathrm{~A}$ list of items that could be represented pictorially in an easily understandable way was generated with consensus reached through 
Table I Demographic and pain characteristics of study participants

\begin{tabular}{lllll}
\hline Variable & Frequency (\%) & Range & Mean & SD \\
\hline Age & & $19-76$ & 50.6 & 14.2 \\
Pain duration (years) & & $0.13-55$ & 12.5 & 12.0 \\
Sex (\% female) & 79 & & & \\
Education & & & & \\
$\quad$ Finished high school & 26.5 & & & \\
$\quad$ Some college & 36.2 & 52 & & \\
Married & 39 & & & \\
Employed (part time or & & & \\
full time) & & & \\
Primary pain location & & & \\
$\quad$ Back & 41.8 & & \\
Lower extremities & 23.6 & & \\
$\quad$ Neck & 9.1 & & \\
Upper extremities & 8.2 & & \\
Diffuse & 3.6 & & \\
$\quad$ Others & 13.6 & & \\
Self-rated activity level & & & \\
Low & 33.0 & & \\
Medium & 46.4 & & \\
High & 20.5 & & \\
\hline
\end{tabular}

Note: $n=|| 3$.

discussion and review of trial sketches. The resulting list of 10 items was used to create draft illustrations to represent polar anchors for a series of common, daily functional quality of life tasks. These illustrations represented common item content from existing self-report functional interference questionnaires: walking, socializing, rising from a chair, climbing stairs, carrying a parcel or moderate-sized item, reaching above shoulder height, engaging in activity outside of the home, sleeping, sports/recreation, and engaging in activities with family. The concept illustrations were presented to a professional illustrator for refinement and enhancement. A 5-point rating scale was incorporated to form the PPIQ (Figure S1). Brief instructions were included in written form at the beginning of the questionnaire and administered verbally (in English) to participants: "for the following questions, please circle a number from 1 to 5 that indicates how much pain affects your ability to participate in the activities shown". Prior to clinical testing, the PPIQ was presented to a group of five pain clinicians for feedback, and all reported the items to be readily understandable.

\section{Validation measures}

Construct validation measures included three psychometrically validated and widely used self-report questionnaires of pain functioning: the PDI, ${ }^{5,8}$ the ODI, ${ }^{7}$ and the interference scale of the Multidimensional Pain Inventory (MPI-Int). ${ }^{9}$ Standardized measures of other important chronic pain dimensions were also included for assessing convergent and divergent validity: pain severity via the Pain Rating Index (PRI), Visual Analog Scale (VAS) and Present Pain Intensity (PPI) scales of the Short-Form McGill Pain Questionnaire (SF-MPQ), ${ }^{40}$ and MPI; distress/negative affect via MPI, Center for Epidemiologic Studies Depression (CESD) Scale,${ }^{41}$ and Positive and Negative Affect Scale (PANAS); ${ }^{42}$ positive affect via the PANAS and CESD; and life control via the MPI.

\section{Procedures}

Participants were recruited and completed study questionnaires immediately prior to scheduled clinic interviews and examinations. After providing informed consent, participants were ushered to a private examination room where they received brief verbal instructions to read and complete the study questionnaires, which they did in paper and pencil format. To control for possible order effects such as response bias due to viewing content of preceding questionnaires administered, a counterbalanced design was employed with the study questionnaires presented to individual participants in random order.

\section{Statistical analyses}

Descriptive and comparative statistics were calculated using GNU PSPP Statistical Analysis Software (Free Software Foundation, Boston, MA, USA). ${ }^{43}$ Construct validity refers to the degree to which an instrument measures what it intends to measure and subsumes all categories of validity. ${ }^{44,45}$ Three types of criterion-related validity were evaluated as indicators of construct validity for the PPIQ. Concurrent validity represents the degree to which the results of a test correspond to those of existing (previously validated) test(s) of the same construct at the same point in time. Convergent validity represents the degree to which two measures that are related according to theory are found to be actually elated. Discriminant validity represents the extent to which measurements that are not expected to be related by theory are in fact unrelated or distinct. All validities were evaluated using Pearson product-moment linear correlations of the PPIQ with the criterion measures. Concurrent validity of individual PPIQ items was also evaluated by Pearson correlation coefficients. Reliability of the scale was evaluated by internal consistency using Cronbach's $a$, a measure of the shared covariance of items. ${ }^{46,47}$

For Cronbach's $a$, a desired coefficient level is generally within the range of $0.65-0.80$ with minimum acceptable level above $0.50 .{ }^{47}$ For validity measures, correlations between tests are limited by the reliability levels of the individual tests. Criterion-related validity coefficients are commonly 
$<0.50$ and rarely exceed $0.60-0.70,{ }^{44}$ a coefficient $>0.45$ has been commonly recommended as an indicator of substantial concurrent validity, and a coefficient $<0.45$ for discriminant validity. ${ }^{48}$ For this study, a coefficient of 0.45 or more was defined as adequate and 0.60 or more as good concurrent validity. For convergent validity, comparisons with measures of different but related constructs introduce additional sources of variance; threshold levels of 0.35 and 0.50 were applied for adequate and good relationships, respectively. For discriminant validity, all comparisons were expected to be negatively correlated, with weaker correlations representing greater discrimination: a correlation coefficient below 0.45 was defined as adequate validity and below 0.30 as good validity. Coefficients for individual item concurrent validities were expected to be lower due to ceilings created by their lower reliabilities when compared with the multi-item scale: 0.35 was defined as adequate validity and 0.50 as good.

\section{Results}

Descriptive statistics for all study measures are presented in Table 2.

\section{Reliability}

The total score of the PPIQ was found to have a high internal consistency coefficient (Cronbach's $a=0.91$ ), suggesting excellent internal consistency ${ }^{46}$ without excess item redundancy. ${ }^{47}$

\section{Construct validity}

\section{Concurrent validity}

Concurrent validity was evaluated through comparisons of PPIQ scores with established measures of functional interference (Table 3). The PPIQ total score correlations with PDI, ODI, and MPI-Int scores ranged from 0.72 to

Table 3 Correlations of PPIQ total score with scales for chronic pain interference, pain severity, and other psychosocial variables

\begin{tabular}{ll}
\hline Scale & PPIQ total score \\
\hline PDI & $0.797^{* * *}$ \\
ODI & $0.808^{* * *}$ \\
MPI-Int & $0.717^{* * *}$ \\
MPI Pain Severity & $0.685^{* * *}$ \\
SF-MPQ PRI & $0.606 * * *$ \\
SF-MPQ VAS & $0.552^{* * *}$ \\
SF-MPQ PPI & $0.446 * * *$ \\
MPI Distress & $0.467 * * *$ \\
CESD & $0.531^{* * *}$ \\
PANAS Negative Affect & $0.395^{* * *}$ \\
PANAS Positive Affect & $-0.292^{*}$ \\
CESD Positive Affect & $-0.373^{* *}$ \\
MPI Life Control & $-0.291 *$ \\
\hline
\end{tabular}

Note: $*_{p}<0.01, *^{*} p<0.001, * * * p<0.0001$.

Abbreviations: CESD, Center for Epidemiological Studies Depression; MPI, Multidimensional Pain Inventory; MPI-Int, Multidimensional Pain InventoryInterference; ODI, Oswestry Disability Index; PANAS, Positive and Negative Affect Scale; PDI, Pain Disability Index; PPI, Present Pain Intensity; PPIQ, Pictorial Pain Interference Questionnaire; PRI, Pain Rating Index; SF-MPQ, Short-Form McGill Pain Questionnaire; VAS, Visual Analog Scale.

Table 2 Descriptive statistics for study measures

\begin{tabular}{|c|c|c|c|c|c|c|c|c|c|}
\hline \multirow[t]{2}{*}{ Measure } & \multirow{2}{*}{$\begin{array}{l}\text { Score } \\
\text { range }\end{array}$} & \multirow[t]{2}{*}{ Min } & \multirow[t]{2}{*}{ Max } & \multirow[t]{2}{*}{ Mean } & \multirow[t]{2}{*}{ Median } & \multirow[t]{2}{*}{ SD } & \multicolumn{3}{|c|}{ Cutoffs for tertile score classifications } \\
\hline & & & & & & & Bottom tertile & Middle tertile & Upper tertile \\
\hline PPIQ & $10-50$ & 13 & 49 & 29.8 & 30 & 9.4 & $\leq 25$ & $>25-33$ & $>33$ \\
\hline PDI & $0-70$ & I & 67 & 33.6 & 35 & 15.7 & $\leq 27$ & $>27-40$ & $>40$ \\
\hline ODI & $0-100$ & 4 & 80 & 36.6 & 36 & 15.6 & $\leq 29$ & $>29-42$ & $>42$ \\
\hline MPI-Int & $0-6$ & 0.3 & 6.0 & 3.8 & 3.9 & 1.4 & $\leq 3.25$ & $>3.25-4.40$ & $>4.40$ \\
\hline MPI Life Control & $0-6$ & 0 & 6 & 3.7 & 4 & 1.3 & & & \\
\hline MPI Distress & $0-6$ & 0 & 6 & 3.2 & 3.3 & 1.4 & & & \\
\hline CESD Positive Affect & $0-12$ & 0 & 12 & 7.2 & 7 & 2.9 & & & \\
\hline CESD Total Depression & $0-60$ & I & 54 & 21.8 & 21 & 12.1 & & & \\
\hline PANAS Positive Affect & $10-50$ & 13 & 47 & 29.4 & 29 & 7.7 & & & \\
\hline PANAS Negative Affect & $10-50$ & 10 & 48 & 23.2 & 23 & 9.2 & & & \\
\hline SF-MPQ PRI & $0-45$ & 4 & 45 & 22.6 & 21 & 9.6 & & & \\
\hline SF-MPQ VAS & $0-10$ & 1.2 & 10 & 6.4 & 6.7 & 2.1 & & & \\
\hline SF-MPQ PPI & $0-5$ & 0 & 5 & 2.3 & 2 & 0.9 & & & \\
\hline
\end{tabular}

Abbreviations: CESD, Center for Epidemiological Studies Depression; Max, Maximum; Min, Minimum; MPI, Multidimensional Pain Inventory; MPI-Int, Multidimensional Pain Inventory-Interference; ODI, Oswestry Disability Index; PANAS, Positive and Negative Affect Scale; PDI, Pain Disability Index; PPI, Present Pain Intensity; PPIQ, Pictorial Pain Interference Questionnaire; PRI, Pain Rating Index; SF-MPQ, Short-Form McGill Pain Questionnaire; VAS, Visual Analog Scale. 
0.81 (all $p<0.0001$ ), suggesting that PPIQ scores provide a good measure of functional interference from chronic pain.

\section{Convergent validity}

The second dimension of construct validity was assessed via convergence of PPIQ scores with measures of other constructs that are known to be related to functional interference: pain severity and affective distress. These measures were expected to be moderately correlated based on having both shared and unique variance in relation to the construct of functional interference. As summarized in Table 3, correlations of PPIQ scores with the MPI Pain Severity, SF-MPQ PRI, VAS, and PPI indices ranged from 0.45 to 0.69 (all $p<0.0001$ ). Correlations with MPI Distress, CESD, and PANAS Negative Affect scales ranged from 0.40 to 0.53 (all $p<0.0001$ ). Thus, the PPIQ exhibited adequate-to-good convergent validity with these measures of pain intensity and negative affect, while also demonstrating expected unique variance.

\section{Discriminant validity}

The third dimension of construct validity was assessed via comparison of PPIQ scores with measures of other constructs that are known to have weak and inverse relationships with functional interference: positive affect and perceived life control. These measures were expected to be negatively correlated with PPIQ scores. That is, higher scores on positive affect and life control would be expected to be associated with lower levels of functional interference. As summarized in Table 3, correlations of PPIQ scores with the PANAS and CESD Positive Affect scales and the MPI Life Control scale ranged from $-0.29(p<0.01)$ to $-0.37(p<0.001)$. The PPIQ exhibited adequate-to-good discriminant validity in relation to these measures of positive affect and life control.

\section{Item validation}

As a measure of item construct validity, scores for individual PPIQ items were correlated with related items from the PDI, ODI, and MPI-Int scales. The number of related items for which correlations were calculated for each PPIQ item ranged from 1 to 3 (Table 4). All coefficients ranged from adequate to good. Correlations were highest for items that most clearly measured the same dimensions of functional interference: PPIQ walking (item 1) correlated 0.61 with the ODI walking item, PPIQ sleep (item 8) correlated 0.69 with the ODI sleep item, PPIQ playing sport (item 9) correlated 0.64 with PDI recreational activity item, and PPIQ socializing (item 2) correlated 0.60 with PDI social activity item (all $p<0.0001$ ). Other PPIQ items related less directly to existing question-

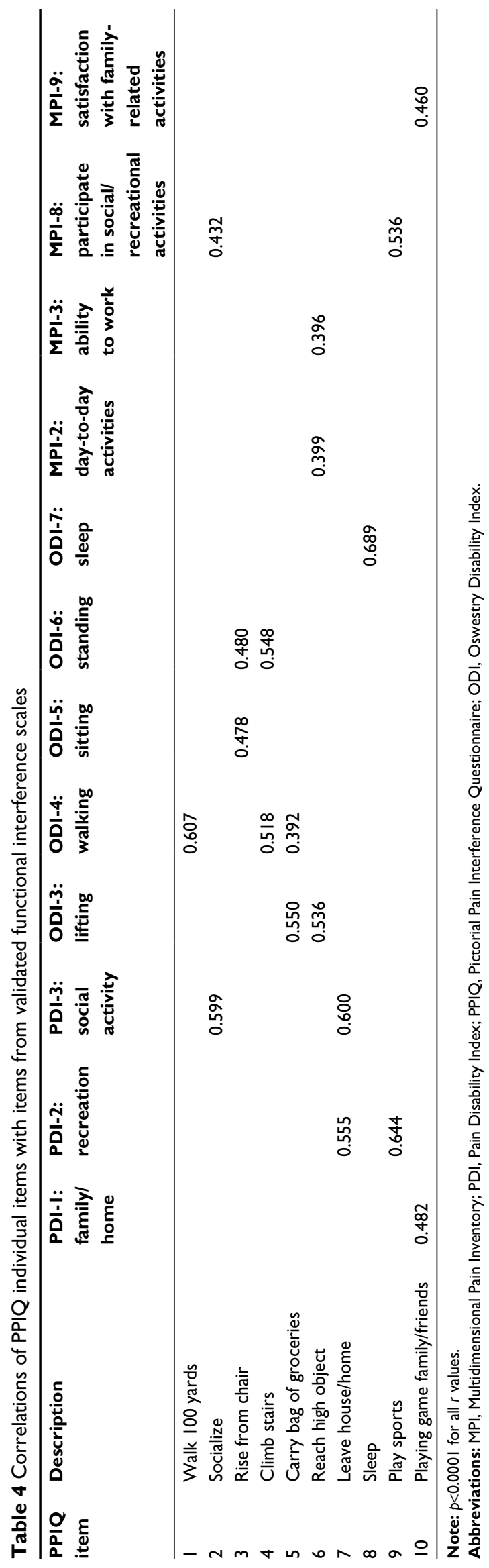


naire items; several of these items had content crossover with items from more than one existing scale: the PPIQ rising from a chair item correlated moderately with the sitting and standing ODI items; the climbing stairs items correlated moderately with the walking and standing ODI items; the carrying bag/parcel item correlated moderately with ODI lifting and walking items; the reaching for high object item correlated moderately with ODI lifting item and to a lesser degree with MPI day-to-day activities and ability to work items; the leaving house/home item correlated moderately with PDI recreation and social activity items $(r=0.40-0.60$, all $p<0.0001)$. The playing games with family/friends item was expected to be related to the PDI family/home activities and MPI satisfaction with family-related activities item and had moderate correlations with both $(r=0.46-0.48, p<0.0001)$.

\section{Score classification}

To enhance clinical utility of the PPIQ, a pilot classification system was developed (Table 5). PPIQ scores were classified as low (25 or lower), moderate (26-33), or high (34 or higher) based on tertile distribution in the development sample. For participants classified in each of the three score ranges, corresponding ranges, medians, and means for the PDI, ODI, and MPI-Int scales are presented in Table 5. Participants with low, moderate, and high PPIQ scores had median PDI scores of 19, 34, and 48, respectively. Similarly, they had median ODI scores of 24, 35.5, and 48, respectively, and median MPI-Int scores of 2.6, 3.8, and 4.8, respectively. Thus, construct validity of the proposed cut scores for classifying low, moderate, and high functional interference levels was supported in the study sample.

\section{Usability/satisfaction}

To assess usability and satisfaction with the PPIQ, participants were asked to provide a single rating of how understandable the items were. The median understandability rating was 1 on a 4-point scale, where $1=$ "very understandable", and $4=$ ="did not understand many". Two-thirds of the participants
(66\%) rated the PPIQ items as "very understandable," while $23 \%$ rated them as "somewhat understandable". Only $2 \%$ expressed the lowest median understandability rating of 4 ("did not understand many"). This suggests that the PPIQ was adequately understood by users overall with the majority of users having no difficulty interpreting the scale items.

\section{Discussion}

A new self-report questionnaire was developed and tested for assessing functional interference from chronic pain via images of common functional activities or tasks to reduce language and literacy requirements. The PPIQ was found to have adequate-to-good psychometric properties in a heterogeneous clinical sample of English-speaking participants with chronic pain. It was well understood by the majority of users and had high concurrence of interference scores with existing language-based questionnaires of chronic pain functioning.

The reported results support the use of the PPIQ to reduce literacy requirements when assessing chronic pain functioning. Literacy levels vary highly in the general population with many adults functioning at the lowest levels of literacy ${ }^{49}$ and $35 \%$ of adults having only basic or below basic level of health literacy. ${ }^{50}$ Thus, validity of results for language-based questionnaires is apt to be compromised among some patients. Clinicians and researchers are unlikely to know when this is occurring due to a common tendency for those with low literacy to mask or not disclose difficulties with reading or comprehension. ${ }^{51}$ For health care facilities providing services to rural and remote, underserved, or low socioeconomic status populations, this problem can be more prevalent. The PPIQ provides a simple and cost-effective alternative to language-dependent questionnaires. Its brief length enhances clinical utility. Future studies with the PPIQ should assess reading level of participants to evaluate psychometric properties in relation to literacy.

A pilot classification system for PPIQ scores was supported by results. This offers a quick and face-valid method to classify participants with chronic pain as low, moderate, or high functional interference producing results that are supported by

Table 5 Classification of functional interference levels based on PPIQ scores

\begin{tabular}{|c|c|c|c|c|}
\hline \multirow{2}{*}{$\begin{array}{l}\text { Functional interference } \\
\text { classification }\end{array}$} & \multirow{2}{*}{$\begin{array}{l}\text { PPIQ cutoffs } \\
\text { (scale range 5-50) }\end{array}$} & \multicolumn{3}{|c|}{ Corresponding scale ranges } \\
\hline & & $\begin{array}{l}\text { PDI range } \\
\text { (median, mean) }\end{array}$ & $\begin{array}{l}\text { ODI range } \\
\text { (median, mean) }\end{array}$ & $\begin{array}{l}\text { MPI-Int range } \\
\text { (median, mean) }\end{array}$ \\
\hline \multirow[t]{2}{*}{ Low } & $\leq 25$ & $|-5|$ & $4.0-46.7$ & $0.3-5.7$ \\
\hline & & $19.0,21.3$ & $24.0,24.6$ & $2.6,2.8$ \\
\hline \multirow[t]{2}{*}{ Moderate } & $26-33$ & $7-49$ & $16.0-60.0$ & $0.8-5.6$ \\
\hline & & $34.0,32.6$ & $35.5,35.2$ & $3.8,3.8$ \\
\hline \multirow[t]{2}{*}{ High } & $\geq 34$ & $16-67$ & $16.0-80.0$ & $2.7-6.0$ \\
\hline & & $48.0,47.0$ & $48.0,50.0$ & $4.8,4.7$ \\
\hline
\end{tabular}

Abbreviations: MPI-Int, Multidimensional Pain Inventory-Interference; PDI, Pain Disability Index; PPIQ, Pictorial Pain Interference Questionnaire; ODI, Oswestry Disability Index. 
existing pain interference scales. For clinicians, this classification system could provide useful information for treatment planning or triaging and for documenting treatment progress and outcomes. For example, an electronic medical record (EMR) system could be programmed to prompt a clinician to consider a physical or occupational therapy referral for patients with moderate or high interference levels. Future studies are recommended to evaluate this type of application. This classification system could also prove useful for research comparing physical, psychosocial, or quality of life variables across different levels of functional interference from chronic pain.

Another potential application of the PPIQ is the assessment of chronic pain interference for LEP or non-Englishspeaking patients. Due to the use of existing language-based measures for validation, the current study included only patients with English fluency. Additional studies will be required to evaluate validity and reliability of the PPIQ in LEP and non-English-speaking patients. If supported by proposed research, the PPIQ could have high utility in clinical settings caring for underserved populations with common LEP and for international clinical trials evaluating chronic pain and treatments in samples with language heterogeneity.

Finally, research to evaluate the PPIQ for assessing pain interference in patients with mild cognitive impairment is recommended. The questionnaire enables the assessment of functional interference through picture recognition and numeric ratings rather than drawing on more demanding receptive and expressive written language skills. With prevalence of mild cognitive impairment in the community estimated to exceed $20 \%,{ }^{20}$ a substantial proportion of individuals with chronic pain could serve to benefit from an alternative assessment modality for self-report of functional interference.

There are several limitations to this study to be considered in interpretation and for planning future research. This was a cross-sectional study, and therefore reliability of the PPIQ over repeat administrations was not assessed. It will be important in future studies to include repeat administration of the PPIQ over a period of several days to weeks, to evaluate test-retest reliability, an important metric of the instrument's reliability. As previously noted, this initial investigation was conducted with a literate and English-fluent sample. Results therefore cannot be generalized to other segments of the chronic pain population with lower literacy and fluency levels, pending further studies, as suggested earlier. Inclusion of cognitive screening in future research could also provide valuable data on the validity of the PPIQ for patients with mild cognitive deficits. Next, although the order of administration of the questionnaires was randomly varied, the inclusion of other language-based questionnaires may have cued some participants to the types of activities or tasks being evaluated. Future studies should evaluate user satisfaction and reliability without concurrent administration of language-based measures of functional interference.

The analyses for this study were based on classical test theory, which has several well-established limitations. ${ }^{52}$ As a result, details of the performance and scaling properties of the individual items that comprise the PPIQ or of relative response patterns for chronic pain subgroups (e.g., based upon age, sex, and pain duration) were not available. Future studies with larger samples would support item analysis via item response theory (IRT) methods, linking items to a common underlying scale to calibrate them and evaluate potential differences in item function between subgroups. Finally, the brief instruction for the PPIQ introduced a language requirement, which would require translation if used with non-English respondents. A pictorial instruction should be developed and tested in future research. This could be compared with written/verbal instruction and no instruction to determine impact on response patterns and results.

\section{Conclusion}

The results of this study have provided initial support for the PPIQ as an alternative to language-based questionnaires for assessing functional interference due to chronic pain in an outpatient chronic pain clinic sample. A classification system for low, moderate, or high functional interference was supported. Future research will help to establish psychometric properties and user response among various chronic pain populations and subgroups, such as individuals with low literacy, LEP, and mild cognitive impairment.

\section{Acknowledgment}

Data collection was supported by funding from the National Institutes of Health (NIH; grant no: R44NS049945-02A1).

\section{Disclosure}

The authors report no conflicts of interest in this work.

\section{References}

1. Andersson GBJ. Epidemiological features of chronic low back pain Lancet. 1999;354(9178):581-585.

2. Osterweis M, Kleinman A, Mechanic D, editors. Pain and Disability: Clinical, Behavioral and Public Policy Perspectives. Washington DC: National Academy Press; 1987.

3. Turk DC, Fillingim RB, Ohrbach R, Patel KV. Assessment of psychosocial and functional impact of chronic pain. J Pain. 2016;17(9):T21-T49.

4. Verbunt JA, Huijnen IPJ, Köke A. Assessment of physical activity in daily life in patients with musculoskeletal pain. Eur J Pain. 2009;13(3):231-242.

5. Tait RC, Chibnall JT. Factor structure of the pain disability index in workers compensation claimants with low back injuries. Arch Phys Med Rehabil. 2005;86(6):1141-1146. 
6. Taylor AM, Phillips K, Patel KV, et al. Assessment of physical function and participation in chronic pain clinical trials: IMMPACT/OMERACT recommendations. Pain. 2016;157(9):1836-1850.

7. Fairbank JCT, Pynsent PB. The Oswestry Disability Index. Spine. 2000;25(22):2940-2953.

8. Pollard CA. Preliminary validity study of the pain disability index. Percept Mot Skills. 1984;59(3):974.

9. Kerns RD, Turk DC, Rudy TE. The West Haven-Yale Multidimensional Pain Inventory (WHYMPI). Pain. 1985;23(4):345-356.

10. Roland M, Morris R. A study of the natural history of back pain: part 1. Development of a reliable and sensitive measure of disability in low-back pain. Spine (Phila Pa 1976). 1983;8(2):141-144.

11. Bech P. Health-related quality of life measurements in the assessment of pain clinic results. Acta Anaesthesiol Scand. 1999;43(9): 893-896.

12. Emery MP, Perrier LL, Acquadro C. Patient-reported outcome and quality of life instruments database (PROQOLID): frequently asked questions. Health Qual Life Outcomes. 2005;3:12.

13. Amtmann D, Cook KF, Jensen MP, et al. Development of a PROMIS item bank to measure pain interference. Pain. 2010;150(1): 173-182.

14. Cook AJ, Clark BR, Schmidt KM, Roberts DA, Nelson KC, Parker BE. Development of a portable, multidimensional computer adaptive testing system for efficient and precise assessment of chronic pain. Poster Presented at: 13th World Congress on Pain (International Association for the Study of Pain); August; 2010; Montreal, QC.

15. Ryan C. Language Use in the United States: 2011; American Community Survey Reports. Washington: U.S. Census Bureau; 2013. Available from: https://www.census.gov/prod/2013pubs/acs-22.pdf. Accessed December 02, 2017.

16. Betancourt JR, Renfrew MR, Green AR, et al. Improving patient safety systems for patients with limited English proficiency: a guide for hospitals. (Prepared by the Disparities Solutions Center, Mongan Institute for Health Policy at Massachusetts General Hospital and Abt Associates, Cambridge, MA, under Contract No. HHSA290200600011I). Rockville, MD: Agency for Healthcare Research and Quality; 2012. AHRQ Publication No. 12-0041.

17. Joint Commission; Division of Health Care Improvement. Overcoming the Challenges of Providing Care to LEP Patients. Quick Safety. Vol. 13. Oakbrook Terrace: Joint Commission; 2015:1-4.

18. Coren JS, Filipetto FA, Weiss LB. Eliminating barriers for patients with limited English proficiency. JAm Osteopath Assoc. 2009;109(12):634-640.

19. Centers for Disease Control and Prevention [webpage on the Internet]. Cognitive Impairment: A Call for Action, Now! 2011. Available from: www.cdc.gov/aging/healthybrain/index.htm. Accessed December 2, 2017.

20. Katz MJ, Lipton RB, Hall CB, et al. Age and sex specific prevalence and incidence of mild cognitive impairment, dementia and Alzheimer's dementia in blacks and whites: a report from the Einstein Aging Study. Alzheimer Dis Assoc Disord. 2012;26(4):335-343.

21. Bernstein AB, Remsburg RE. Estimated prevalence of people with cognitive impairment: results from nationally representative community and institutional surveys. Gerontologist. 2007;47(3):350-354.

22. Kincaid JP, Fishburne RP Jr, Rogers RL, Chissom BS. Derivation of New Readability Formulas (Automated Readability Index, Fog Count and Flesch Reading Ease Formula) for Navy Enlisted Personnel. Millington, TN: Naval Technical Training Command Research Branch; 1975. Available from: http://stars.library.ucf.edu/cgi/viewcontent.cgi? article $=1055 \&$ context $=$ istlibrary. Accessed December 02, 2017.

23. Flesch RF. A new readability yardstick. J Appl Psychol. 1948;32(3): 221-233.

24. Bergström G, Jensen IB, Bodin L, Linton SJ, Nygren AL, Carlsson SG. Reliability and factor structure of the multidimensional pain inventory Swedish language version (MPI-S). Pain. 1998;75(1):101-110.

25. Ferrari R, Novara C, Sanavio E, Zerbini F. Internal structure and validity of the multidimensional pain inventory, Italian language version. Pain Med. 2000;1(2):123-130.
26. Mannion AF, Junge A, Fairbank JC, Dvorak J, Grob D. Development of a German version of the oswestry disability index. Part 1: crosscultural adaptation, reliability, and validity. Eur Spine J. 2006;15(1): 55.

27. Mousavi SJ, Parnianpour M, Mehdian H, Montazeri A, Mobini B. The Oswestry Disability Index, the Roland-Morris Disability Questionnaire, and the Quebec back pain disability scale: translation and validation studies of the Iranian versions. Spine. 2006;31(14): E454-E459.

28. Soer R, Köke A, Vroomen PCA, et al. Extensive validation of the pain disability index in 3 groups of patients with musculoskeletal pain. Spine (Phila Pa 1976). 2013;38(9):E562-E568.

29. Guillemin F, Bombardier C, Beaton D. Cross-cultural adaptation of health-related quality of life measures: literature review and proposed guidelines. J Clin Epidemiol. 1993;46(12):1417-1432.

30. Garra G, Singer AJ, Taira BR, et al. Validation of the Wong-Baker FACES pain rating scale in pediatric emergency department patients. Acad Emerg Med. 2010;17(1):50-54.

31. Kuttner L, Lepage T. Face scales for the assessment of pediatric pain: a critical review. Can J Behav Sci. 1989;21(2):198-209.

32. Turk DC, Robinson JP, Sherman JJ, Burwinkle T, Swanson K. Assessing fear in patients with cervical pain: development and validation of the pictorial fear of activity scale - cervical (PFActS-C). Pain. 2008;139(1):55-62.

33. Harris CV, Bradlyn AS, Coffman J, Gunel E, Cottrell L. BMI-based body size guides for women and men: development and validation of a novel pictorial method to assess weight-related concepts. Int $J$ Obes (Lond). 2008;32(2):336-342.

34. Baxter AL, Watcha MF, Baxter WV, Leong T, Wyatt MW. Development and validation of a pictorial nausea rating scale for children. Pediatrics. 2011;127(6):e1542-e1549.

35. Klis S, Vingerhoets AJJM, de Wit M, Zandbelt N, Snoek FJ. Pictorial representation of illness and self measure revised II (PRISM-RII) - a novel method to assess perceived burden of illness in diabetes patients. Health Qual Life Outcomes. 2008;6:104.

36. Ernst M, Cookus BA, Moravec BC. Pictorial instrument for children and adolescents (PICA-III-R). J Am Acad Child Adolesc Psychiatry. 2000;39(1):94-99.

37. Dubi K, Schneider S. The picture anxiety test (PAT): a new pictorial assessment of anxiety symptoms in young children. $J$ Anxiety Disord. 2009;23(8):1148-1157.

38. Shneidman ES. The psychological pain assessment scale. Suicide Life Threat Behav. 1999;29(4):287-294.

39. Bradley MM, Lang PJ. Measuring emotion: the self-assessment manikin and the semantic differential. J Behav Ther Exp Psychiatry. 1994;25(1):49-59.

40. Melzack R. The short-form McGill pain questionnaire. Pain. 1987;30(2):191-197.

41. Radloff LS. The CESD-D scale: a self-report depression scale for research in the general population. Appl Psychol Meas. 1977;1: 385-401.

42. Watson D, Clark LA, Tellegen A. Development and validation of brief measures of positive and negative affect: the PANAS scales. J Pers Soc Psychol. 1988;54(6):1063-1070.

43. Free Software Foundation, Inc. PSPP Users' Guide: GNU PSPP Statistical Analysis Software, Release 1.0.1-g818227. Boston, MA: Free Software Foundation, Inc; 2016.

44. Murphy KR, Davidshofer CO. Psychological Testing: Principles and Applications. Upper Saddle River, NJ: Pearson/Prentice Hall; 2005.

45. Drost EA. Validity and reliability in social science research. Educ Res Perspect. 2011;38:105-123.

46. Gliem JA, Gliem RR. Calculating, Interpreting, and Reporting Cronbach's Alpha Reliability Coefficient for Likert-Type Scales. Presented at the Midwest Research-to-Practice Conference in Adult, Continuing, and Community Education. Columbus, OH: Ohio State University; 2003. 
47. Goforth C [webpage on the Internet]. Using and Interpreting Cronbach's Alpha. 2015. Available from: http://data.library.virginia.edu/using-andinterpreting-cronbachs-alpha/. Accessed February 24, 2017.

48. Devon HA, Block ME, Moyle-Wright P, et al. A psychometric toolbox for testing validity and reliability. J Nurs Scholarsh. 2007;39(2):155-164.

49. Kirsch IS, Jungeblut A, Jenkins L, Kolstad A. Adult Literacy in America: A First Look at the Findings of the National Adult Literacy Survey. 3rd ed. Washington, DC: US Department of Education; 2002.
50. US Department of Health and Human Services [webpage on the Internet]. America's Health Literacy: Why We Need Accessible Health Information. 2017. Available from: https://health.gov/communication/ literacy/issuebrief/. Accessed October 15, 2017.

51. Beder H. The stigma of illiteracy. Adult Basic Educ. 1991;1(2):67-78.

52. Hayes RD, Morales LS, Reise SP. Item response theory and health outcomes measurement in the 21st century. Med Care. 2000;38(9 suppl):II28-II42. 


\section{Supplementary material}

\section{Pictorial Pain Interference Questionnaire}

For the following questions, please circle a number from 1 to 5 that indicates how much pain affects your ability to participate in the activities shown:

1. 2
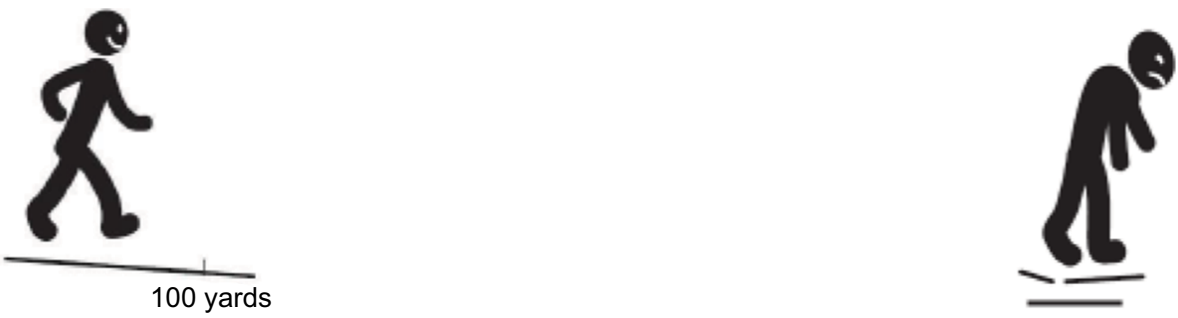

2.

1

2

5

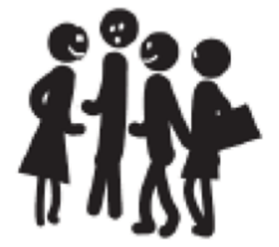

3.

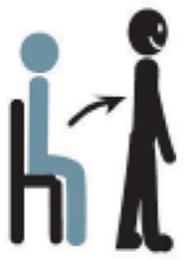

2

3

4

5

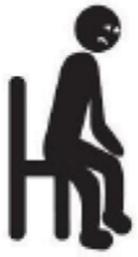

Figure SI (Continued) 
4.

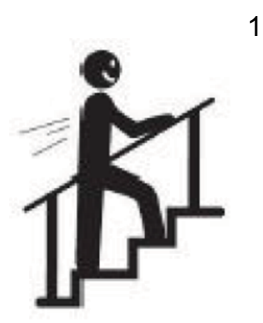

5.

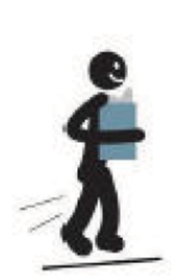

6.

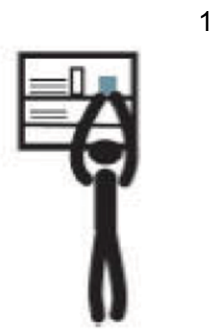

2

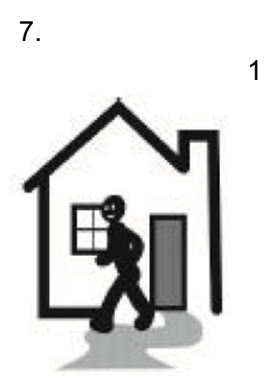

Figure SI (Continued)
3

3

4

5

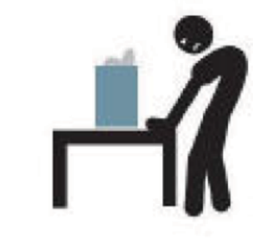

4

5
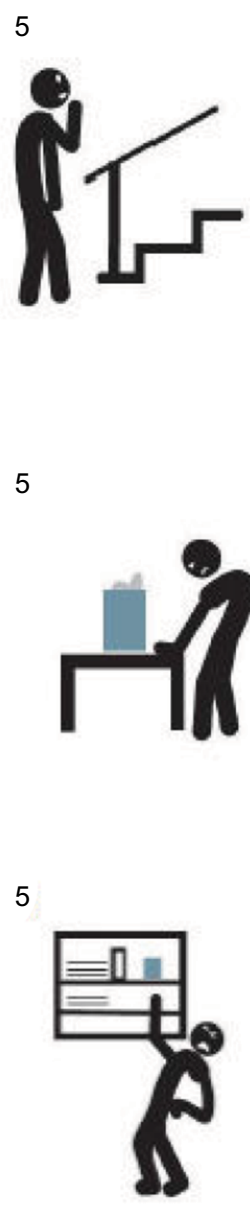

3

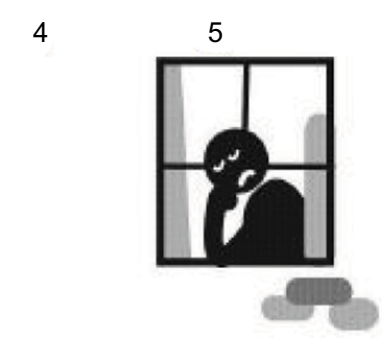


8.

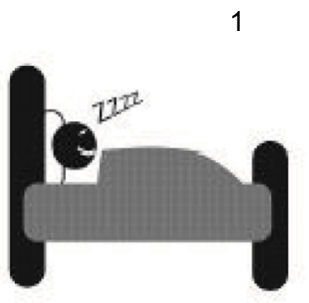

4

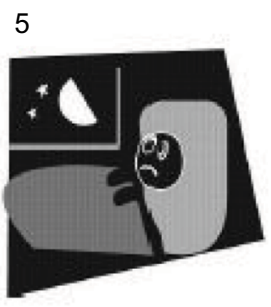

9.

1

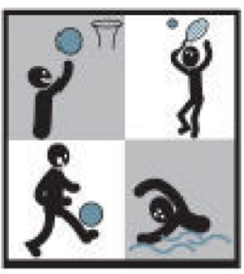

10.

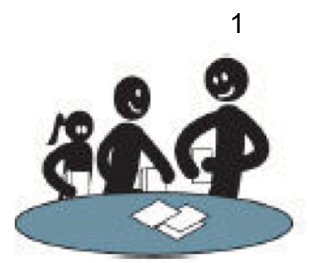

Figure SI Pictorial Pain Interference Questionnaire.
2

3

4

5

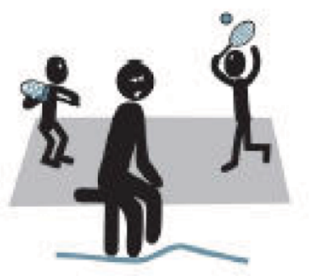

4

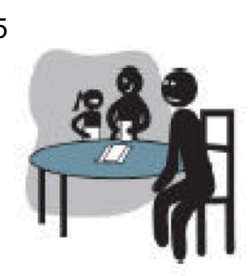

3

5

\section{Publish your work in this journal}

The Journal of Pain Research is an international, peer reviewed, open access, online journal that welcomes laboratory and clinical findings in the fields of pain research and the prevention and management of pain. Original research, reviews, symposium reports, hypothesis formation and commentaries are all considered for publication.
The manuscript management system is completely online and includes a very quick and fair peer-review system, which is all easy to use. Visit http://www.dovepress.com/testimonials.php to read real quotes from published authors. 